\title{
EENIGE TOELICHTINGEN
}

\author{
TOT DE
}

ПMĚNANGKABAUSCH-MALEISCHE ZAMENSPRAKEN, OPGESTELD DOOR

SI-DAOED RADJA MEDAN, HOOFD-ONDERWIJZER VAN DE

INLANDSCHE SCHOOL TE PADANG. - 'S GRAVENHAGE,

MARTINUS NIJHOFF, 1872."

Deze zamenspraken, door den hoogleeraar J. Pijnappel uitgegeven met het goede doel om "een eerste begin te maken" met het bestudeeren van het Mĕnangkabausch-Maleisch, schịnnen nog weinig de aandacht tot zich getrokken te hebben van de beoefenaars van Oostindische taalstudie. Zou dit zijn te wijten aan te geringe belangstelling om eene taal aan te leeren die algemeen gesproken wordt in de Padangsche Bovenlanden, of aan onverschilligheid omtrent dit bijna eenig hulpmiddel dat daartoe is aangeboden, of aan onbekendheid met het bestaan van dit boekje? Naar 't mij voorkomt, is 't veeleer toe te schrijven aan zeker besef van onvermogen om met deze gegevens deze taal, ja zelfs deze zamenspraken, te leeren verstaan.

Ook de uitgever schịnt hiervoor gevreesd te hebben, reeds bij 't schrijven zijner voorrede; want, na de juiste opmerking (bladz. I en IV) "dat de heer S. Stibbe", die hem deze zamenspraken met "woordverklaringen en vertalingen en andere verduidelijkingen " heeft bezorgd, "zich daardoor voor de Oostindische taalkeunis zeer verdienstelijk gemaakt heeft " en dat "alle aanstaande beoefenaars van het Měnangkabausch-Maleisch, zoo zij billijk willen zijn, dat zullen moeten erkennen," verneemt men deze gulle doch tevens onwelkome belijdenis : "M et dat al is het er echter ver van af, dat ik, na die inlichtingen te hebben ontvangen, op de hoogte zou zijn om die zamenspraken zoo uit te geven en te verklaren als ik zou verlangd hebben "

Dit doet immers te dezen opzichte weinig hopen op 't veilig 4de Volgr. II. 
geleide van dezen gids, die bovendien niet alle inlichtingen geeft die hij zelf mocht ontvangen; want de hem verschafte vertalingen en verduidelijkingen zijn achterwege gelaten. Met recht mag men dus zeggen dat men in dit boekje niet de noodige aanwijzingen heeft gevonden, en dat men, om het te kunnen gebruiken, naar andere hulp moet omzien.

Zulk eene aanmerking uit te spreken zonder eenige hulp aan te bieden, ligt niet in mijne bedoeling. En mochten nu sommigen wellicht beweren dat ik zoo doende mij schuldig maak aan onbehoorlijke aanmatiging, - dan zal ik niet trachten mij te verdedigen door te betuigen dat deze toelichtingen van een ander zijn, maar integendeel stel $i \mathrm{k}$ gaarne mij verantwoordelijk voor de mededeeling van deze welgemeende poging; niet alle bezwaren zijn er door weggeruimd, maar toch blijkt een ernstig streven om zoo goed mogelijk den weg te wijzen op dit, ons nagenoeg nog geheel onbekend, gebied. Ziehier het geval.

Toen in 1875 de heer W. Hoogkamer, die sinds jaren ter plaatse dit dialekt heeft leeren kennen, gedurende zijn kort verblijf hier te lande, mij bezocht, vroeg ik hem deze Zamenspraken te doorloopen en van eenige toelichtingen te voorzien. Aan dit verzoek heeft hịj terstond voldaan, niettegenstaande zijn tijd zeer beperkt was, en allerlei ounstandigheden hem verhinderden om zijne aanteekeningen of andere hulpmiddelen te raadplegen. Het zijn dus deze toelichtingen welke ik nu hier namens hem aanbied, doch niet zonder mij verontschuldigd te hebben voor 't lang oponthoud, veroorzaakt door langdurige ziekte en de gevolgen daarvan; ik hoop te toonen dat het geene onverschilligheid was, die zoo lang mij weerhield deze toelichtingen uit te geven, door weldra nog eene kleine bijdrage tot de kennis van dit dialekt te leveren.

Daar het te bespreken boekje, behalve de Zamenspraken yan Si-Daoed Radja Medan, eene woordenlijst van den heer S. Stibbe bevat en de voorrede van dr. J. Pijnappel, zoo zijn ook de toelichtingen van den heer W. Hoogkamer drieledig; eenige, welke op de voorrede betrekking hebben, handelen vooral over de uitspraak; andere zijn van lexicalen aard, en de weinige overige betreflen, als om een voorbeeld te geven, de eerste regels van deze Zamenspraken. Geldt bị al deze toelichtingen de reeds gemaakte opmerking dat het mijn gewilligen vriend toen aan tijd en gelegenbeid ontbrak om rustig te overwegen en de noodige vergelijkingen te maken, ik twijfel er niet aan 
of zijne bijdrage zal toch erkentelijk worden ontvangen, en ik hoop hartelijk dat hij en anderen zich zullen aangespoord gevoelen om onze hoogst gebrekkige kennis van dit dialekt verder aan te vullen. 1

De kennis van het Mĕnangkabausch 2 is namelijk dringend noodzakelijk, en dus van grooter belang dan men uit de voorrede van dr. P. zou vermoeden. Met duidelijke aanwijzing dezer, noodzakelijkheid begint de heer $\mathrm{H}$. zijne toelichtingen. Ik laat ze hier volgen. Mijne bijvoegsels heb ik met J. gemerkt.

\section{A. W. T. JuYnboli.}

\section{Toelichtingen van den heer W. Hoogkamer.}

Beginnen we met de voorrede, waar we op bladz. II, regel 8 van boven en verder, deze woorden van professor Pijnappel vinden :

"In die streken (namelijk de Padangsche Bovenlanden) kon "men zich met het gewone Maleisch behelpen, en daarbij is "het schrift, waarmee die taal geschreven wordt, het Maleische, "de woorden zijn Maleische, en wie het gewone Maleisch spreekt "wordt er verstaan; dat de inlanders onder elkaar een tongval "spreken, waarvan men naauwelijks een woord begrijpen kan, "daarop heeft men niet veel gelet, daar de behoefte om dien "te leeren zelden moest gevoeld worden."

$\mathrm{lk}$ ben zoo vrij daaromtrent op te merken dat men zich nooit in die streken met het gewone Maleisch heeft kunnen behelpen; en dat wie het gewone Maleisch daar spreekt, door niemand wordt verstaan dan hoogstens door enkele hoofden, handelaars, politie-oppassers en door bedienden die veel in aanraking zijn geweest met Europeanen. Wil men zich dus verstaanbaar maken voor den-

1 De in dit dialekt geschreven en door de heeren J. J. Van Limburg Brouwer en L. K. Harmsen uitgegeven stukken, voorkomende in het 2le en 23e deel van het Tijdschrift van het Bataviaasch Genootschap, worden misschien een volgenden keer besproken.

2 "Deze Maleische tongval kent de ĕ niet," schreef dr. H. N. Van der Tuuk in het Tijdschr. Bat. Gen. XVIII, bladz. 126. Moet men dit dialect derhalve niet Mănangkabausch (of Minangkabauscb) noemen in plaats van Měnangkabausch? 
geen tot wien men spreekt, dan moet men bijna altijd in die streken de volkstaal gebruiken, d. i. dien tongval welken de inlanders onder elkaar spreken. De beh oefte om dien te leeren kennen wordt dus terstond door ieder gevoeld die daarvreemd a ankomt. 1

Dat " het schrift, waarmee die taal geschreven wordt, het gewone Maieische" zou zijn, is ook niet geheel juist, zooals men reeds eenigermate uit het op bladz. V gezegde zou kunnen opmaken, waar sprake is van "'t gewend raken aan de bijzonderheden der Maleische spelling" namelijk in dit dialekt. De niet licht aan te leeren uitspraak der klinkers, en zoo ook, aan 't eind der woorden, van sommige medeklinkers, wijkt sterk van 't gewone Maleisch af, maar kan toch in 't MĕnangkabauschMaleische schrift zeer duidelijk uitgedrukt. worden; en in zoo ver dit geschiedt, is er tusschen 't schrijven van dit dialect en het schrijven van 't gewone Maleisch een vrij groot onderscheid. 2

Daarenboven schrijven vele onbedreven inlanders, vooral in hun brieven, vaak zoo als de uitspraak luidt; en die uitspraak verschilt voor hetzelfde woord dikwijls aanmerkelijk met de uitspraak in 't gewone Maleisch. Wie zou bijv. dô èh en tjôpè' herkennen uit het gewone Maleisch dĕras en tjĕpat? En bovendien vindt men in zulke inlandsche geschriften dikwijls hetzelfde woord op twee of meer verschillende wijzen in den zelfden brief geschreven. En brieven van verschillende inlanders toonen dat gebrek aan consequentıe nog sterker bij onderlinge vergelijking.

1 Er hestaat dus naar het schịnt voor jeder die in de $\mathrm{Pa}$ dangsche bovenlanden met den inlander wil omgaan, even veel reden om Mănangkabausch te kennen, als voor anderen bijv. op Java om Javaansch enz. te verstaan.

J.

2 De voorbeelden die de heer H. daarvan geeft, heeft hij genomen uit de op bladz. VII der voorrede genoemde woorden; hij toont daarmede aan, dat er wel degelijk regelmat in acht kan worden genomen in 't schrijven van zulke woorden in Maleisch schrift. Uit gebrek aan teekens kunnen wij echter deze voorbeelden hier niet afdrukken. De lezer zal voorts bemerken dat ik voorzichtigheidshalve de wijze van transscriptie der Mănangkabausche woorden van den heer H. onveranderd heb gelaten. 
Dit maakt de studie natuurlijk lastig. Doch waarom zouden wij hun niet kunnen leeren consequent en zooveel mogelijk grammaticaal te schrijven?

Door daarentegen de Hollandsche letter in plaats van de Maleische bij 't schrijven van 't Mĕnangkabausch te stellen, zou men, dunkt mij, de verwarring zeer bedenkelijk doen toenemen, daar men toch ook vele aan 't Hollandsch vreemde teekens zou moeten overnemen en uitdenken, zooals uit de meeste hier gegeven voorbeelden reeds eenigermate blijkt.

Ook de woorden zijn niet de gewone Maleis he; want zij verschillen zeer dikwijls in uitspraak, of in vorm of in beteekenis.

Voorbeelden van verschil in uitspraak zijn de zooeven genoemde woorden dôrè h en tjôp è'.

Verschil in vorm is o. a. merkbaar in de Mĕn. woorden baroeh, djandjang en himbau, die in 't gewone Mal. bawah, tangga en panggil luiden.

Verschil van beteekenis is bijv. op te merken in de volgende woorden:

la pèh of lôpèh Mĕn. = toestemmen, voorbij zijn; daarentegen is lĕp as gewoon Mal. = vrïj, los;

pondo' (q) Mĕn. = kort; pondok in 't gewoon Mal. hut. 1

Doch ook uit de aanteekeningen van professor P. blijkt voldoende dat het Mernangkabausch een dialect is dat zeer sterk afwijkt van 't gewone Maleisch.

Zijne aanteekeningen, op bladz. VIII en verder, omtrent de uitspraak der letters, hebben de verdienste van zeer duidelijk en geordend weer te geven wat elders verspreid aangetroffen wordt. Op de hier en daar voorkomende vragen zal ik trachten te antwoorden.

Op bladz. VI wordt, naar aanleiding der opmerking: "in vele woorden heeft de open $a$ eene uitspraak, welke met die

1 Een niet onaardig voorbeeld van verschil vind ik in $P$ ijnappel's Maleisch-Nederduitsch Woordenboek. In beide talen komt namelijk het woord $r \bar{a} m \bar{i}$ voor; doch het Maleische $r \bar{a} m \bar{i}$ beantwoordt aan 't Mănangkabausche $r \bar{a} m i n$, en het Mănangkabausche $r \bar{a} m \bar{i}$ is gelijk an het Maleische $r \bar{a} m e i$. Het Maleische djangan = Mănangk. oesah, doch 't Mănangk. djangan = Mal. dĕngan. ${ }_{\text {Downtoaded from Brill.com04/25/2023 11:21:42PM }}$ 
van de fransche $e u$ overeenkomt en deze wijst de $\breve{a}$ an ;" door den heer P. gevraagd: "Maar is die uitspraak dan aan geen regels gebonden?" - Daarop moet ik antwoorden dat ik die uitspraak der open $a$ als de fransche eu nooit heb opgemerkt; althans ik herinner mij dat niet. Maar stellig hoorde ik (zie de eerste woorden der eerste zamenspraak, bladz. 3) menărik steeds manaarie'(q) uitspreken, en bănar altijd bána (r), de' $r$ namelijk uit te spreken als de Engelsche $r$ in shore.

Omtrent de woorden (bladz. IX) djoea, as a, timba enz. zij opgemerkt dat de uitspraak werkelijk luidt alsof achter de $a$ op 't eind de Engelsche $r$ uit shore of prefer stond, zoodat de opgegeven woorden aan niets_anders, dan 't geen door den heer V. d. T. is gezegd, kunnen doen denken.

De vraag (op dezelfde bladz.) of de Mĕn. Maleijer de $k$ aan het eind van een woord wel goed articuleert, is ontkennend te beantwoorden; vandaar dat hij bij 't schrijven van die $k$ of $q$ zeer willekeurig is, door die veelal of geheel weg te laten of te vervangen door een hamza.

Voor 't behouden of weglaten der $h$ aan het eind van een woord geldt als regel, dat de $h$ geschreven wordt als de uitspraak luidt voor den uitgang:

ah met lichte aspiratie en verlenging der $a$, samen of afzonderlijk ;

ih als ie ëh, beter iejh / deze $\ddot{e}$ is stom en de $h$ zeer oeh als oeëh of oewh licht geaspireerd.

Aangaande de wijzigingen der klinkers vóór de medeklinkers (bladz. X), zij opgemerkt dat de oet en oep minder nog als o e i worden uitgesproken, dan wel als oej. - Hierbij vermeld ik ook nog de afwijking in uitspraak van de klinkers oe en ie vóór de slot-ng; bijv.

$\mathrm{kampoeng}$ luidt als $\mathrm{k}$ ampoewng.

koenieng als koeniejng, enz.

Ook hoorde ik sommige woorden eenigermate anders uitspreken, als daar vermeld wordt. Bijv. kardjô hoorde ik meer karádjô dan kadjô, artô meer rátô dan atô, en dastar meer dêta(r) dan dètô uitspreken.

Het wegvallen van de $k$ in de uitspraak (bladz. XI, regel 8), ook na een vokaal, is zeer algemeen.

De woorden djawa, djiwa, bawa heb ik steeds hooren. uitspreken djôwô, djiw ô en baw ô ' (q). 
De opmerking omtrent de woorden manô enz. (bladz. X̀II, regel 5) komt mij zeer juist voor 1 . De eerste $a$ wordt echter uitgesproken als onze $a \boldsymbol{a}$.

Kònô hoorde ik niet; wel kanê of kanei. Rasô verschilt van rasei, doordat dit laatste woord waarschijnlijk is rasaï. Nooit hoorde ik rasoï; evenmin lôdang voor ladang; doch wel tôbang voor tabang en gôdang voor gadang.

Wat omtrent de verandering van de slot- $m$ in $n$ gezegd is, geldt, voor zoo ver mij bekend, slechts voor de beide genoemde woorden baloem en malim 2 .

Behalve poenja en soenji, veranderende in poenô en soeni, worden ook boenji en semboenji tot boeni en samboeni. ${ }^{3}$

Ook komt de $b$ wel eens in plaats van de $w$ en omgekeerd, zooals watas gelijk batas. En de $m$ wordt verwisseld met $b$, bijv. minantoe wordt ook wel binantoe; evenzoo de $m$ met $p$, als gamoe' (q) gelijk ga po e' (q); en de $s$ met $t j$ als soeroet gelijk tjoeroet.

Meer overeenkomstig met de uitspraak zou (bladz. XIII, regel 3 en v.) geschreven zijn a a, namelijk ba'-a a, ba raa, sia a, maa. Joch wat over $\mathrm{maka}$ en $\mathrm{mama}$ gezegd is (regel 5) begrijp ik niet; want $\mathrm{maka}$ komt veel voor, ook wel als redegevend woord; - $\mathrm{m}$ a ma wordt $\mathrm{ma}^{\prime}(\mathrm{q})$.

De vraag botreffende de drie onderdialecten van 't Mĕnangkabausch ${ }^{4} \mathrm{kan} \mathrm{jk}$ niet beantwoorden. Alleen kan ik daaromtrent meedeelen dat de uitspraak $a$ en $\hat{\sigma}$ in pl. v. $е$, behalve in Agam

1 Reeds in $\mathbf{1 8 5 5}$ was dit vast gebruik opgemerkt door $\mathrm{Mr}$. W. A. Henny, in het Tijdschrift van het Batav. Genootschap, IVe deel, bladz. 405 .

2 In de woordenlijst is ook lazin opgegeven als gelijk lazim; en er zijn waarschijnlijk nog wel meer woorden waarin die verandering plaats heeft.

J.

3 Ook koeniq Măn. = k o enjit Mal. geeft V.d. T. op in zijne Tobasche spraakkunst, bladz. 30 ; en zoo is ook njijoer in 't Măn. nijoer; njiroe=niroe, en narih $=n j$ arih.

J.

4 "De taal der lubus, en die van $\mathrm{U} J u$ is een tongval van 't Mănangkarbousch Maleisch." (Van der Tuuk, Bataksch leesboek, IV, bladz. 20.) 
en Tanah-Datar ook in de L Kota de gewone is, en dat ik ook steeds bôrèh, dôkè' of dakè', lòlò'(q), lôkèh of lakèh maar nooit kònô, kò kò' of tiola heb gehoord.

Omtrent de woordenlijst heb ik het volgende op te merken.

A.

$\mathrm{A}, \mathrm{alah}=\mathrm{apôlah}$, zou men voor de duidelijkheid a alah moeten schrijven, ter onderscheiding van alah = talah of ôlah.

$\mathrm{A}$ b è ${ }^{2}$ heb ik nooit gehoord; doch steeds ob éj, dat onderzoeken beteekent $=$ priqsa, nitgesproken als pri'sô; obéj 2 $=$ onderzoek goed, let op, luister.

Ag ô. Dit a gô $=$ ongeveer, komt veel als stopwoord voor in de spreektaal (zie bij ga); - agô ${ }^{2}=\mathrm{kiro}{ }^{2}=$ denken, gedachte; ag $\hat{o}^{2 \mathrm{k}} \mathrm{an}=$ bij benadering opgeven of bepalen; tarag $\hat{o}=$ schatten.

A hap voor ahad heb ik nooit gehoord; ahad wordt uitgesproken a'k ad of ô'kad = Zondag.

Aïr = ajar, ook wel ä̈j.

Ala; juister alah of ôlah; ook lah; het is hetzelfde als talah, dat in de spreektaal minder in gebruik is dan de afgeleide vormen van dat woord.

$\mathrm{Alèh}=$ alas; dit moet veranderd worden in galas, dat uitgesproken wordt gálè h. De eigenlijke beteekenis is marskramen, zooals bijna alle Maleische kleinhandelaren doen: 1

$\mathrm{Ambi}=\mathrm{ambil}$; uitgesproken $\mathrm{amb \hat { \imath }}$; niet te verwarren met $\mathrm{hambat}$, uitgespr. a mb ̀̀ $=$ tegenhouden, beletten . Amping = hampir; uitgesproken ampiejng; ook = d âk è of dôk è'.

Anda' = handaq; veel komt voor de vorm (h) anda' (q) nja $=$ ' $t$ is wenschelijk, liefst, zoo mogelijk.

Andei $=$ moeder; meer gebruikt men mandei; ook amei of $\operatorname{atji}(q)=\operatorname{otji}^{\prime}(\mathrm{q})$.

Ang $=g \ddot{i}$; heter $=j \ddot{i j}$ ('t zij gemeenzaam, 't zij vernederend). Awa'(q) ang is iets beleefder, en awa'(q) kan men tot iederen inlander zeggen, die geen recht

1 Alas komt werkelijk nevens' galas voor in 't West-Sumatraansch, in de beteekenis van "rondventen, als marskramers, ook met kippen, eenden, enz." Zie Nix bij Von de Wall, Maleisch Woordenboek. J. 
op den aanspraaktitel van datoe' $(q)$ heeft en voor wien men toch beleefd wil zijn. 1

Angkoe is een soort van aanspraaktitel, dien men wel eens bezigt bij hoofden of fatsoenlijke inlanders.

Angga, uitspr. anggô, hangt zeker samen met hinggô en ang g a. ${ }^{2}$

Antjoe is niet slechts in de benedenlanden, maar ook in de bovenlanden gebruikelijk.

A p ô; men hoort veel minder ba' a a pô dan ba'-a a, in de beteekenis van hoe? wat? welk?; p a ng a pan $=$ pĕng a$\mathrm{pa-a} n$, en beteekent, doch slechts in verbinding met hari - niet zonder dat woord zooals hier vermeld is - hoe laat; eigenlijk hoe (is de stand van) de(n) dag (zon)? of welk (gedeelte van) de(n) dag (is het)? Asa $=$ asal $=$ het Arabische atsal, doch in de Maleische boteekenis van: als, indien; - as a djen $=$ as a djangan = als 't maar niet; - as a, ook = één (telwoord). Zie ook tji ê' (q).

$\mathrm{A}$ tè $\mathrm{h}=\mathrm{atas}$; di a tè $\mathrm{h}-\hat{\mathrm{o}}$ (mij onbekende vorm) is misschien $=\mathrm{di}-\mathrm{atèh}-\mathrm{nj} \hat{\mathrm{o}}$ of di-atè $\mathrm{h}-\mathrm{n} \hat{\mathrm{o}}=$ daarenboven . A tô $=$ harta; wordt meer uitgesproken als rátô. A wa' (q); awa'ô ken ik niet; wèl: $i k=a w a^{\prime}(q)$ manl. en vrouwl. = a wa' $(q)$ dèn $\left(m\right.$. en vr.) $=a w^{\prime} a^{\prime}(q)$

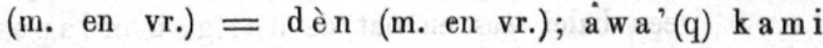
(meerv. m. en vr.) en awa' (q) hambo (enkelv. m. en vr.). $G i j=$ awa'(q) m. en vr., doch awa' (q) ang (m.) en awa' (q) kau (vr.); ang (m.) en kau (vr.). $H \ddot{i j}$ en $z \ddot{j}=$ awa'(q) injô, awa'(q) njô, awa' (q) nô.

\section{B.}

$\mathrm{Ba}^{\prime}(\mathrm{q})=$ sapáráti (sapěrti).

Bakô (?) zal moeten zijn ba êkô $=$ meteen, straks, uitgesproken bêkô; de $a$ hoort men bijna niet. De uitdrukkingen $\mathrm{b} a$ atè $h \mathrm{tan}$ en $\mathrm{ba}$ di baroeh tan

1 Bị mij heeft zich wel eens een hoofd beklaagd over oneerbiedigheid van een zijner ana' (q) boeah, die hem met ang had aangesproken. 't Komt vrij wel overeen met 't leelijke loe, elders zoo veel in gebruik.

$\mathrm{H}$.

${ }^{2} \mathrm{Angga}^{2}$ is in 't West-Sum. = neen schudden, en anggo' $=j a$ knikken. Zie Nix in voce. 
(tan $=$ itan $=$ daar ginds) beteekenen daarboven, daarbeneden; bakini kan beteekenen ba'(q) kini $=$ zooals $n u .{ }^{1}$

$\mathrm{Badar}$ is een kleine vischsoort, waarvan op Padang een soort namaak van Makasaarsche roode vischjesı wordt gemakt; maar beteekent niet:- gedroogde visch; hoewel de $\mathrm{b}$ ada $\mathrm{r}$ soms ook wel eens gedroogd gegeten wordt. B a gô $=$ ba(r)agô $=$ a gô.

Bä̈nah is een zeer bekend Arabisch woord.

$\mathrm{B}_{\text {a } і \mathbf{r}}=$ bajar wordt ook wel uitgesproken als bajaa (r), ( $r$ als in shore).

Bakô moet zijn baêk ô $=$ straks, meteen; baiêkố malam $=$ van avond.

Balau hoorde ik nooit; wel baliaw, en dat komt veel voor, sprekende tot of over zijn meerderen in rang of stand. Balei is nooit markt; (markt is pakan), maar een balei staat wel vaak op marktplaats; het is namelijk de vergaderplaats der hoofden en bevolking bij 't bespreken van negari-belangen.

In den zin, voorkomende op bladz. 32 regel $3 \mathrm{v}$. o. Hambo mâ kabălei malihè djaga, die ook kan zijn: hambô mâ kabali'(q) malihè dja gô, is 't mogelijk dat bedoeld wordt dat op de pakan een balei was en dat de dangau of la pau, waarin eten werd verkocht of snuisterijen, aan spreker behoorende, dicht bij de balei stond en dat hij dus met bovenstaande uitdrukking te kennen wilde geven dat hij daarheen ging. Misschien zou de bijvoeging van dan den zin duidelijker maken nl. Hambô mâa kabalei dan malihè djagô djoê̂.

Balik = bali'(q) uitgesproken balie'(q).

Banah zal wel niets anders wezen dan bána (r). Dat woord beteekent meestal : werkelijk, stellig, zeer, erg, euz. maar is niet gelijk aan kirônja; kirônja bana r is: werkelijk, ' $t$ was zoo.

Bara $=$ barapô; uitgesproken baráa.

Baroeh = bawah; uitgesproken baroewh.

Batong moet zijn batoeng, uitgesproken batoewng.

1 Dit ba' of baq is 'tzelfde als ' $t$ Maleische bag $\mathrm{i}$, zooals V. d. T. opmerkt in zijn Bat. Woordb. bladz, $364^{b}{ }^{\circ}$ 
Batè $h=$ batas $=$ watè $h=$ watas.

Batoe = batoe $(r)=$ bĕtoel.

Binantoe $=$ minantoe $=$ mernantoe.

Boe è' = boeah; dit is een fout; in plaats van boeah leze men boeat.

Boejoeng, uitgesproken boejoewng, zegt men sprekende tot kleine jongens; een vader spreekt zoo tot zijn zoon. Bolah = brilah is'mij onbekend; wel ken ik barilah $=$ agihlah $=$ geef.

Bôrèh = bĕras; ook bárèh.

\section{D.}

Da voor indah; juister dô voor iend ôh.

Da p̀̀' = dapat is ook ontmoeten.

Datoe' is de aanspraaktitel van een panghoeloe, en wordt ook uitgestrekt tot dien van ieder fatsoenlijk inlander, of gebezigd als men tot zijn meerderen spreekt (altijd tot mannen natuurlijk).

Dè van oendéj, niet on dei. Men hoort echter meer oendéj dan dè of $d e ́ j$, een klagenden uitroep.

Dè' wordt ook na karana en na olih gebruikt; de uitdrukking onder 4) ? brapô dè' la mô is mij niet bekend. Dèn zie bij $a w a^{\prime}(q)$.

Dènga = dĕngar; beter danga (r) of dônga (r). Kad̆̌$\mathrm{ngaran}$ wordt in de uitspraak kadangôran, of zelfs kanóran.

$\mathrm{Dj}_{\mathrm{j}}$ is mij niet bekend; wel $\mathrm{dji} \hat{o}=$ met, aan $=\mathrm{dje}$.

$\mathrm{Dja}^{\prime}=$ sedert, is eene afkorting van sadja' (q).

Djaga, uitgespraken djag $\hat{o}$, ook wel dj êgô, beteekent zoowel de wacht doen of houden, als ook een la pa u of dangau (soort van kraam) houden waarin men eten bereidt en verkoopt of snuisterijen uitstalt.

Djalang; mandjalang poekoel ampat $=$ bijna vier uur; soerat ini datang mandjalang = deze brief kome tot $u$ of geworde $u$. Djôlong ${ }^{2}=$ moela moela is natuurlijk een ander woord.

Djandjang = trap, ladder; maar tjantjang of tjintjang beteekent aan stukken hakken, en heeft niets gemeen) met djandjang.

Dja rang $=$ wijd uit, verspreid, dun, doorschïnend van kain. 
$\mathrm{Dj}$ awat is ook ontvangen, de verantwoordelijkheid van iets op zich nemen.

$\mathrm{Dj}$ è h $=\mathrm{lah}$ is mij onbekend.

Djô, moet zijn djiô; zie bij dja.

A dj ô wordt steeds geheel uitgesproken. Op bladz. 46, regel 9 beteekent djiô met.

Djoewa $=$ djoewal, uitgesproken djoewa(r); djoeô $=$ djoegô $=$ djoega.

D ô; op bl. 17, regel 1 staat $\mathrm{d}$ a, maar ik begrijp niet hoe de vorm d o e (bladz. 16) ooit als d a kan worden gelezen. Stellig beduidt dat op die plaats doea, uitgesproken doeô; zoodat de zin dan beteekent: "Niet veel vader; (als ik) zoowat twee toekar (heb) is "t genoeg."

Naar aanleiding van de verwijzing naar bladz. 30, 1 v. o., waar $\mathrm{d} \hat{o}$ niet gelijk $\mathrm{di} \hat{o}$ is, zij opgemerkt dat men, sprekende tot iemand, vaak 't woord oedô (afgekort tot $\mathrm{d} \hat{o})=$ mïn broer, mïnheer bezigt en dan alleen $\mathrm{d} \hat{o}$ laat hooren.

D o êó; ba doeô batig ô beteekent, geloof ik, bï hoopjes van twee en van drie.

Dò k̀ is mij onbekend.

Dôrèh = dĕras, wordt ook d a r è h uitgesproken.

Dosanak, ook wel dansana'(q) en badansana'(q) beteekent broer of zuster $=$ an aqsabadan?

E.

$\mathrm{Ek} \hat{\mathrm{o}}=$ è kor, uitgesproken i $\mathrm{ekoe}(\mathrm{r})=$ staart.

i e koe (r) kôtô $=$ ' $t$ laagst gelegen deel der kota;

$\mathrm{k}$ apalô $\mathrm{k} \hat{\mathrm{t}} \hat{\mathrm{o}}={ }^{\prime} \boldsymbol{t}$ hoogst gelegen gedeelte daarvan.

Elò', uitgesproken êlô'(q); êlồ $(\mathrm{q})^{2}=$ netjes, fink.

Esoe'; barêsoe'(q) tadi = barêsoe'(q) tjakô; s a êsoe' $(\mathrm{q})$, uitgesproken sêsoe' $(\mathrm{q})=$ te eeniger tïd.

G.

$\mathrm{Ga}_{\mathrm{a}}=\mathrm{aga}=\mathrm{ag} \hat{\mathrm{o}}$.

$\mathrm{Gadih}=\mathrm{gadis}$; niet te verwarren met gadei.

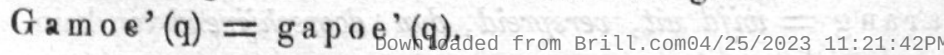


Garang is ook sterk, fameus.

$\mathrm{Gata}=\mathrm{g}$ ĕtah; doch is ook gatal, uitgesproken gata(r) dat jeukend beteekent.

Gen is mij onbekend;

Gilô evenzoo in den aangegeven zin.

\section{H.}

Had ̀' $=$ hadap; mahadò' (q) beteekent ook: iemand aankijken.

$\mathrm{Hag} \hat{o}=\mathrm{harg} \hat{o} ; \mathrm{ik}$ hoorde dat steeds vitspreken als rágô $\mathrm{Hamb}$ at. Zie bij ambil.

Hamoen of a moen is bepaaldelijk schelden.

Han ${ }^{\prime}(\mathrm{q})=\mathrm{h}$ an a $\mathrm{p}=$ zich stilhouden.

Harò' = hadap, is een fout; dit moet rijn hadò'.

Hila. Dit moet zijn hêlô; mahêlô.

$\mathrm{Himbau}$ beteekent ook kennis geven.

$\mathrm{H}$ o e $\mathrm{ni}$ beteekent ook bewonen.

\section{I.}

$\mathrm{Ijo}_{\mathrm{j}}=\mathrm{io}=\mathrm{ia}$; iokan $=$ bevestigen.

$\mathrm{Ik}$ at uitgesprokeu ik è'.

$\mathrm{Ik} \hat{\mathrm{o}} ; \mathrm{ka} \mathrm{ik} \hat{\mathrm{o}}=$ hier heen $; \mathrm{baik} \hat{\mathrm{o}}=\mathrm{ba} \hat{\mathrm{e} k} \hat{o}=$ straks.

$\operatorname{Inj} \hat{o}=\operatorname{inja}=\mathrm{i} a=h \ddot{j}$.

Intah is mij onbekend; wel hoorde ik antah $=\mathrm{tah}=\mathrm{toh}$. Itan $=\hat{t}$ tèn $=\tan =\mathrm{t}_{\mathrm{n}} \mathrm{n}=\mathrm{itoe} ; \mathrm{pa}$ ît èn of pîtèn $=$ ginds, dáár.

\section{K.}

$\mathrm{Ka}^{\prime}=\mathrm{kaka}^{\prime}(\mathrm{q})$.

$\mathrm{Kadj} \hat{o}=\mathrm{kĕrdjô}$, heb ik steeds hooren uitspreken $\mathrm{karádj} \hat{o}$ of karôdjô.

Kalamei moet zijn galamei of goelamei, een soort van inlandsch zoet gebak.

$\mathrm{K}$ a n ja' kan èn hierheen en daarheen, is mij onbekend; hierheen is $\mathrm{ka}$ iko of $\mathrm{kania}$; daarheen is $\mathrm{kasinan}$ of kakioen $=\mathrm{kakên}=\mathrm{kên}=\mathrm{kiên}$.

$\mathrm{K}$ aping is mij onbekend.

K a p o k eigenlijk ka po e' $(\mathrm{q})=$ groote mand, en dan : rijstschuur. 
$\mathrm{Karak}=\mathrm{k} \breve{\mathrm{rak}}$, uitgesproken karô $=$ korst, laag.

Karèh $=$ kĕras, ook uitgesproken kôrè h; niet te verwarren met $\mathrm{k}$ a rat, uitgesproken $\mathrm{k}$ a r $\mathrm{e}^{\prime}=$ snïden, hakken.

$\mathrm{K}$ a u, namelijk het tweede, is mij onbekend. 1

$\mathrm{Ki}$ èn $=\mathrm{k} \hat{\mathrm{e}} \mathrm{n}$, zie hierboven.

Kimat heeft met himat niets te maken. 't Woord kimat is 't Arabische qîmat $=$ prijs.

Koekoeh $=$ rijp; koekoe' $(\mathrm{q})=$ 't kraaijen van een haan.

$\mathrm{L}_{\text {a } \mathrm{i}}=\mathrm{ada}$, en zelden $=$ lagi.

L akè' (= l ěkat, eigenlijk kleven, ) heeft den zin van aantrekken van kleeren, en van opleggen van medicijnen, daar de meeste inlandsche medicijnen voor uitwendig gebruik zijn en op 't lichaam worden gelegd of gesmeerd.

L akèh - lĕkas; ook uitgesproken lôk è h; men gebruikt veel meer tja pè of tjôpè en dôrèh of darèh.

Lamboe ${ }^{\mathrm{i}}=\mathrm{lamboeh}$; ook loewa' (q).

Lamô; dja salamô, beter dja’ (q) salamô, d. i. van vroeger af.

La p è h = lěpas; ook wel lôpè h, beteekent ook toestemmen, voorbij zijn.

La poe. Ik meen dat dit woord is lapoe'(q); lapau is een soort van inlandsche gaarkeuken.

L a tak beteekent ook leggen, ta lata' (q) liggen.

Lawak; lawa'(q) beteekent vleesch, uitgesproken la o ' (q); een moct visch heet ook wel eens la o e' (q).

Kaloear, eigenl. uitkomen (hier, uit de negarie). Loeroeh = loeroes; men zegt ook loeroej.

\section{M.}

Ma (beter mahaa) vormt met ikô een buitengewoon dikwijls gebezigd stopwoord, dat soms wel eens beduidt: $z i e-$ hier, hiernu, enz.; maar 't welk uitgesproken wordt als ikô maháa (klemtoon op de 2e lettergreep, en de $h$ geaspireerd). Voor maka doet 't dus natuurlijk dik-

\footnotetext{
1 Nix, bij Von de Wall, Maleisch Woordb., bak a u $=$ hampir.
} 
wijls dienst; voor mana nooit; want de afkorting van dat woord spreekt men uit $\mathrm{maa}$; evenmin voor $\mathrm{m}$ ang a pa, want dat wordt $\mathrm{mang} a \mathrm{a}$; en de afkorting van $\mathrm{mama}^{\prime}(\mathrm{q})$ is $\mathrm{ma}^{\prime}(\mathrm{q})$.

De onderstelling onder NB. voorkomende is dus juist. $\mathrm{Mala}$, eigenlijk malah, is als 't ware bestorven in den mond van den inlander en is in de meeste gevallen niets dan een stopwoord.

Mani, koralen, zoowel steenen als glazen en echte.

Mantarô en samantarô = 't gewoon Maleisch samantara. Masah; zeker een drukfout; er staat op bladz. $38 \mathrm{masak}$ en terecht; masa'(q) toch beteekent gekookt, rïp , gereed; en masa' (q) roendieng heeft dus ongeveer de beteekenis die in de lijst is opgegeven.

M a of mòh? zie a moh. Ma oe zou juister geschreven zijn; $\mathrm{m}$ ò h, afkorting van a mòh, beteekent zooveel als : begrijpt ge, vindt ge 't goed, wilt ge, enz.; in hoe ver dit woord samenhangt met ma oe weet ik niet. 1 Moendjoeng lees moentjoeng, uitspr. moentjoewng. Mongkô $=\mathrm{karana} ; \mathrm{maka}$ als redegevend woord komt veel voor, maar wordt hoogst zelden mougkô, veel makô uitgesproken.

\section{N.}

$\mathrm{N}$ in. Waarom zou op bladz. 52 , regel 7 , niet even goed en beter $\mathrm{n}$ an te lezen zijn? $2 \mathrm{Op}$ bladz. 35 heb ik dat woord $\mathrm{n}$ in niet kunnen vinden.

$\mathrm{Nja}$. "Soms in plaats van het gewone 6." Mogelijk is 't toch juister te zeggen: $\hat{b}$ in plaats van 't gewone $n j a$ of $\mathrm{nj} \hat{o}$, dat zelfs wel $\mathrm{na}$ of $\mathrm{n} \hat{o}$ wordt.

$\mathrm{Nja}$ ' als afkorting van inja $=$ injô, zou juister geschreven zijn $n j \hat{~ o ̂}$.

$\mathrm{Nji}$ is mij onbekend, evenals nja' voor ikô zooals op bladz. 30 reg. 14 en bladz. 39 reg. 1 v. 0.

1 Nix, bij Von de Wall, Maleisch Woordb., onderscheidt a moe $=$ willen van a moe $\mathrm{h}^{2}=$ met elkaar overleggen, beraadslagen.

2 Ja, want nin, een verkorte vorm van inin, is immers slechts in poèzy gebruikelijk? Zie V. d. T., Bat. leesb., IV, bladz. 199, n. 1. 
O voor $n j a$ of $n j \hat{o}$ of $n \hat{o}$ heb ik vaak gehoord.

Oekoer, uitgesproken oekoe(r). Men zegt toch meer sapaqat en sapôqat dan samoepaqat.

Oentoe' $(\mathrm{q})=$ aan.

Oepik; vitgesproken oepie'(q) of pie'(q).

Oer è' = oerat is ook spier en ader; 't werkwoord heeft ook de beteekenis van pidjid, en wordt daarvoor steeds gebruikt.

Oesoe $=$ oesoel; de pluralis namelijk van 't Arabische atsal begin.

[Het volgende o e soer, beletsel, is het Arabische 'odr. J.]

P.

$\mathrm{Pa}=$ apô; juister pô; pabila en apabila $=$ pabilô en apabiiô.

Padahkô is mij niet bekend.

Padoesi, ook paradoesi.

$\mathrm{Pak} \hat{o}=$ pĕkak is goed, en heeft ook de beteekenis van doof. Palang; alang kapalang is een zeer gebruikelijke uitroep. P a p a, éénstemmig; 't woord is p a p a t, uitgesproken p a pè', en wordt veel met $\mathbf{r a p a t}$ in één adem gehoord; $\mathrm{r}$ a pè p a pè = éénstemmig.

Paroei = pĕroet; uitgesproken paroej, poeroej en poeroe. Patang, namiddag, na afloop van 't middaggebed totdat 't donker wordt. Patang ${ }^{2}$ hari $=$ in den avond; $\mathrm{nan}$ kapatang $=$ die van gisteren avond of die van gisteren. Uitgesproken ook pôtang.

Patjah; patjahlah parang $=$ de oorlog brak uit, d. i. men begon te vechten.

Patji' $=$ patjit $=$ vasthouden, grijpen; vatten .

$\mathrm{P} \grave{\mathrm{e}}=\mathrm{ik} \hat{\mathrm{o}}$; mij onbekend.

Poeroe en koerô zijn, voor zooveel mij bekend, twee soorten van huidziekte; bij sakit poeroe zijn voornamelijk de beenen als bedekt met groote steenpuisten en gaten, terwijl sakit koerò' $=$ k oe rap $=$ schurft is.

Pôkô ken ik niet in de beteekenis van hoofdpersoon, maar wèl in die van uitgave, onkosten, 't kapitaal dat men in eene zaak had gestoken. 


\section{9}

Pondo' $(\mathrm{q})=$ kort. Men hoort meer singkéj.

\section{R.}

Rantah, weer een drukfout? want op pag. 57 regel 6 staat maranta' (q), niet marantah; het beteekent: opvliegen, op den grond stampen, slaan.

Roending, uitgesproken roendiejng. Saboeah roending beteekent een speech of praatje; maar 't eens zijn is sa pandap̀̀' roending.

\section{S.}

Sabat $=$ sabab. Men hoort steeds sábá $(q)$.

Saka staat voor sakar, uitgesproken sáká(r), en beteekent een koekje, 't zij anau-suiker 't zij gambier.

$\mathrm{S}$ a moen djèn saka (r), op bladz. 33, reg. 17, beteekent roof en moord.

$\mathrm{S}$ a larô; die grootte is niet bepaald.

Sarikat komt af van 't Arab. sjarîkat.

S a rong, uitgesproken sa roewng.

Silang, ook wel uitgesproken sèlang, beteekent ook kruisen. Singk ò', voor singkap, beteekent in singk ò hari pagi $=$ bij 't aanbreken van den dag.

Soe ${ }^{2}$; tangan soê schrijft men soêh h, welke $h$ men in de uitspraak eenigszins laat hooren.

T.

Ta'; tah kò = tò' k ò = mogelijk, misschien.

Tabang = těrbang, ook uitgesproken trabang.

Tadak; di hambôta'tadaki; 't grondwoord is daki= klimmen; tadaki $=$ tĕ $\mathrm{rdaki}=$ te beklimmen. In den aangewezen zin beteekent het eigenlijk: ik ga niet meer naar boven. Pandakian $=$ hoogte, helling.

[Ta dôg ô; zou dit niet van dôgô afkomen, of dòk ò', eu dat dan gelịk zịjn aan het gewoon Maleische děk ap? Men vergelijke bijv. kòkò'=kěkap, of lòlò'= lĕlap. Misschien is tadòkò' (= těrdĕk a p) te lezen? Zie bij dòkò.

Takô = tjakô. 
Tan $=\hat{\text { itan }}=$ itoe.

Tandei; tandeinja = laal 't maar, 't komt er niet op aan = béarlah.

$\mathrm{T}$ awa $=\mathrm{tawa}(\mathrm{r})=\mathrm{tawa}(\mathrm{l}) ;$ ook inwrijven met obat die gewijd is door den priester, ouder 't prevelen van gebeden.

$\mathrm{T}$ è $=$ sakètèk $=$ sakêtjế(q) $=$ sakênê'(q).

Tidôf $=$ tidak, is mij niet bekend.

Tjiè; ook as a; beter tji ê'(q).

Toedjoe; katoedjoean $=$ in de richting van, op gelijke hoogte; iets dat iemand lijkt of bevalt;

Toenggoe, manoenggoe = geregeld manen.

Toetoeb = toetoep, uitgesproken toetoe' (q); rimbô batoetoe'(q) = zwaar bosch.

Zien we nu de Zamenspraken in, dan stuit men terstond op 't verschil van den tekst in Hollandsche en in Maleische letter, wat den aanvanger in twijfel brengt omtrent de bedoeing. Ik laat daar 't onvolkomen teruggeven der klinkers, maar waartoe letters weggelaten, bijgevoegd of veranderd?

Nemen wij bijv. den eersten zin van de eerste zamenspraak, op bladz. 2 en 3 :

In het Maleisch parampoewa; in het Holl. prampoean,

$\begin{array}{llll}\text { " } & \text { bardjoewa; } & \text { " } & \text { bādjoeā, } \\ \text { " } & \text { manarie'(q) } & \text { " } & \text { menărik, } \\ \text { " } & \text { njāa, } & \text { " } & \text { sāwah, } \\ & \text { " } & \text { nja enz. }\end{array}$

Daar 't volgende even weinig consequent is, is 't onnoodig hierop verder te wijzen; want in plaats van hulp door de transscriptie te geven in het lezen dezer Zamenspraken, schept de uitgever nieuwe moeilịjkheden, - vooral voor iemand die aan 't Mĕnangkabausch nog niets gedaan heeft. Ware echter tusschen haakjes gezet of gecursiveerd waar de uitgever meende in de Holl. transscriptie te moeten afwijken van de Maleische schrijfwijze, dan zou aan 't genoemd bezwaar te gemoet zijn gekomen. Het begin bijv. was aldus duidelijker:

Parampoea(n) bardjoea(l) bali. Laï ka'(q) (a)kan manari'(q) sawa(h) nja' toean hambôsasa'(q) banar dè'(q) (h)oetang? kò'ka'(q) lai soekô, tari'(q) djoea (l)a(h) sawah hambô (a)ga(') saloepô'(q) nan ba' (q) di baroeh (î)tan. 
Men kan hier de vraag stellen, of schrijver, de onderwijzerer Si-Daoed Radja Medan, zich ten taak gesteld heeft te schrijven zooals gesproken wordt, dan of hij den ongeschonden vorm van 't woord heeft willen bewaren? Het antwoord daarop luidt voor beide vragen ontkennend en bevestigend tevens: dan eens wèl, dan eens niet.

Zoo schrijft hij bijv. in den aangegeven zin parampoea, terwijl de ongeschonden vorm van 't woord is parampoean, en bardjoewa, terwijl de ongeschonden vorm is bardjoeal, omdat men de woorden uitspreekt parampoea en badjoea(r) enz. Daarentegen schrijft hij $s a b a b$, met $s a b a t$ in de transscriptie, als aangevende de uitspraak saba'(q)? enz.

Bleek voorts uit dit voorbeeld reeds genoegzaam dat de naukeurigheid der transscriptie veel te wenschen overlaat, ook de Maleische tekst is zeer onregelmatig; vaak vindt men, niet minder dan in de vroeger genoemde brieven, in denzelfden zin hetzelfde woord op twee of meer verschillende wijzen geschreven.

Meermalen ben ik verplicht geweest deze zamenspraken hard op te lezen, en dat dikwijls te herhalen; zoo doende hoorde ik dan soms wat bedoeld was op plaatsen waar een eenvoudige lectuur mij in 't onzekere had gelaten. En echter voeg ik er onmiddellijk bij, dat ik niet geslaagd ben om ze allen te begrijpen. 1

Toch meen ik dat men in ieder geval ook den heer P. dankbaar moet zijn voor zijn arbeid. Mogelijk kan die de aanleiding worden dat men later nieuwe zamenspraken zal uitgeven, waarin beter rekening wordt gehouden met de eischen der spelling zoowel in Holl. als in Maleisch schrift; daarbij zal dan een uitgebreider en correcter woordenlijst goeden dienst doen om den tekst verstaanbaar te maken, ook voor hen die deze taal nog niet hadden leeren kennen.

\section{W. Hoogkamer.}

1 Dat de correctie van den tekst ook te wenschen overlaat, bewijst de lijst van opgegeven drukfouten, die stellig niet volledig is; althans reeds op bladz. 4, regel 11 zie ik baa a o staan, wat ba āpo moet zijn, zooals ook op bl. 5 staat; want de zin is: " Heb je ook gehoord hoeveel de padi jaarlijks oplevert?, 